\title{
The Buckley and Casson Prize: Some Reflections
}

\author{
Mark Casson, University of Reading, UK
}

ThE HIGH QUALITY OF WORK SUBMITTED for the Peter J. Buckley and Mark Casson AIB Dissertation Award affirms the vitality of IB research, and the importance of doctoral research to the scholarly community in general. Previously known as the Richard N. Farmer Dissertation Award, it is awarded to the best Ph.D. dissertation in IB completed in the previous year. I have been a member of the judges' panel for the past four years, and was chair this year. I am now standing down, and so it is an appropriate time for me to reflect on my experience as a judge.

The "best dissertation" is, of course, the best dissertation in the opinion of the judges. As you would expect, different judges have different opinions, and so these opinions need to be aggregated in order to arrive at a collective decision. There are many possible rules for aggregation, and different people prefer different rules. This year the committee drew up a short list of five from thirty submissions. The short-listing was done on the basis of abstracts and supervisors' recommendations only. The four judges then each read all of the short-listed dissertations in full. Each judge ranked the dissertations from one (top) to five (bottom) with no equal ranks. No judge (including the chair) knew the other judges' rankings at the time they decided their rankings. The chair calculated the sums of the ranks, and this year the criterion identified a provisional winner. Precedent dictated an additional requirement; namely that the winner was the first choice of at least one judge, which was indeed the case. The first and second-ranked candidates were very close, however. After further consultation, it was decided, by majority vote, that the prize should not be shared, and the provisional winner was thereby confirmed. Throughout this process the panel received outstanding support from the AIB Secretariat.

Why do I tell you all this? Firstly, people have a right to know, in my opinion. Secondly, it illustrates an important methodological point. It shows that decisions are made by individuals, not by committees. Committee procedures simply make it possible to aggregate decisions. All committee members are then morally implicated in the resultant decision, unless they resign or publicly disassociate themselves from it. Finally, it shows that, while information can be shared within a committee, sharing information can be bad as well as good. If one judge knows how other judges have voted, for example, they can vote strategically by giving the lowest rank to the closest competitor of their favoured candidate. We may therefore conclude that no committee, or any organisation composed of committees (such as a firm), has a "mind" of its own. Someone, such as the chairman or CEO, may well make the rules, but only if they are an autocrat can they guarantee to make the decisions themselves. Regulating communication is no bad thing under certain circumstances; it may hold the key to producing a fair outcome. It can be seen that the awarding of the Buckley and Casson AIB Dissertation Award involves exactly the same sort of strategic issues that govern the organisational structure of a modern corporation.

There are more strategic issues to consider. In my opinion there are two main kinds of theses that make it to the Buckley and Casson AIB Dissertation Award short-list. I call them the "high-risk" and "low-risk" varieties. The high-risk thesis is radically novel; it investigates an issue on which there is little or no existing literature, or uses a data source that no one else has used before. The low-risk thesis, by contrast, makes an important contribution to an existing field of literature; its dataset is original, but the source of the data is one that has been used before. I naturally incline to the high-risk thesis-I like my research to be exciting. When you are driven by curiosity, as I am, you have to take risks. Those who incline to the low-risk thesis favour soundness and reliability. When I consider the IB profession, I have to say that I think that high-risk people like myself are in a minority. As regards the Award Committee itself, I would say that, on average, the membership has been evenly balanced in the past. I still see a problem though. Low-risk judges seem to be more intolerant than high-risk judges; high-risk theses that get top grades from risk-lovers seem to get bottom grades from risk-avoiders, whereas high-risk people can generally see merit in low-risk theses too. Where it has been a close call in the past, therefore, it has generally been the low-risk thesis that has won. But, as they say, no system is perfect, and where the call is close it is unreasonable for anyone to dissent from the most straight-forward decision.

I worry, however, about the career prospects of these high-risk researchers. If the Buckley and Casson AIB Dissertation Award committee is mildly conservative in the type of work it rewards, I think the IB profession is positively reactionary on this issue. IB journals -including the very top journals - are full of safe, low-risk research. Statistical theory distinguishes between Type I and Type II errors. If we take the null hypothesis as "This paper contains no errors" then a Type I error involves wrongly rejecting the null (accepting a flawed paper) whilst a Type II error involves wrongly accepting the null (rejecting a paper that contains no error). Many journal editors are obsessed with Type I errors; they aim to not publish papers that contain any errors. In the process they are willing to sacrifice other papers as victims of Type II errors.

Novel papers are deemed more likely to contain errors than unoriginal papers, and so unoriginal papers are preferred by risk-avoiders. But the idea that papers published in leading journals contain no errors is absurd. It is generally admitted that until recently numerous IB articles were published with common variance problems, or with regressions that involved endogeneity biases, or even both. In my view human fallibility almost guarantees that every published paper contains an error somewhere, even if it never comes to light. Errors are a consequence of uncritical reliance on secondary literature, utilising other people's dodgy data, unwarranted leaps in logic, and so on. Journal reputation affords no immunity against error. If more editors would admit this, we might have more interesting journals to read, and our short-listed candidates would get their work published more quickly.

The natural format in which to publish a thesis is a book-namely the traditional academic monograph. Slicing up a major piece of research like a Ph.D .dissertation into bite-size chunks of 8,000 words and publishing them in different journals is hardly a good recipe for communicating a big idea. Yet books, we are told, don't count. It is said that books aren't properly refereed. 
In my experience this is incorrect. But even if it were correct, it should not be overlooked that books are reviewed - unlike confidential referee reports, the comments and criticisms of reviewers are highly public. If you read through Alan Rugman's book of IB book reviews, you will see the risks that book authors ran when Alan was on the loose.

We're also told that people don't read books anymore. But e-books, read on laptops or kindles, are changing all that. Books used to be expensive, but e-books are quite cheap, and sales of academic e-books are booming. I hope that our Buckley and Casson AIB Dissertation Award finalists will consider publishing their theses as books, and not just as articles. As Alan Rugman
What are the objectives of the profession? What are the resource constraints on achieving those objectives? How many different models are there for organizing professional activities, and which is the best model, given the objectives and the constraints? In practice the IB profession, like most other professions, uses mixed modes of organization. There are non-profit membership organizations like AIB; non-profit employers like universities and their business schools; and for-profit businesses like private publishing houses producing books and journals. These organizations operate in markets for specialist knowledge-based activities such as education, research, and consultancy. Problems can arise from the market environment, from imbalances between the different types of organization, and from problems internal to organizations themselves. Some of these potential problem areas are under the control of the IB community and some are not. noted, Stephen Hymer, John Dunning, Peter Buckley, Alan, myself and many others all built their early reputations through books rather than articles. Of course, producing a book requires a bit of effort-the literature review needs to be streamlined, the theory expressed more concisely, the context explained better, and so on. But revising a thesis to produce a book can be much more rewarding intellectually than dismembering a thesis into a series of unrelated articles. Showing how everything hangs together is intellectually more stimulating than examining how far everything can be pulled apart.

The Buckley and Casson Award finalists, despite of their magnificent achievements, are faced with daunting hurdles in building their careers. Many will become probationary employees of large institutions that set their faculty unrealistic publications targets, requiring them to endlessly revise and resubmit to journals whose editors are proud of their rejection rates. How do we explain in rational terms why new entrants to the profession are given such a gruelling time? It seems to be the same old story-the senior academics make the rules in the interests of-guess who? - the senior academics. Unrealistic publication targets make line management easier for Deans; they ensure that almost everyone is doomed to fail-junior staff can therefore be hired or fired on the basis of personal preferences rather than actual merit. The same thing applies with journals. By protecting referees with anonymity and condoning their condescension (and sometimes downright rudeness), editors can ensure that every paper when submitted has something wrong with it. The editor can then tell the author how to put it right-in some cases virtually dictating the content of the paper to them. Of course, there are exceptions; the problem is that the "good guys" (male or female) are the exception rather than the rule.

So what will happen to our finalists? Most will undoubtedly succeed in their academic careers. But when they achieve success, will they simply step into the shoes of their oppressors? Will they become the target-setters and rejectionists of the future? I sincerely hope not. There's got to be a better way to organise IB studies if the IB profession is to nurture new talent rather than just alienate it. But what is this better way, and how do we achieve it?

I began by analysing the Buckley and Casson Award as an exercise in applied organizational studies. Why not do the same to the IB profession as a whole?
Many of my IB colleagues seem to believe that the IB profession is not in control of its own destiny. They lament the way that young researchers have missed out on the "golden age" of IB research, when big ideas were matched only by big expense accounts and when business schools were still quite small. They don't blame the IB community for running out of ideas; they just blame market forces instead. Market forces are certainly more hostile now than they used to be; in many universities expansion has given way to costcutting, and the value and impact of research is increasingly questioned. Changes in contracts of employment and in intellectual property rights mean that faculty have less discretion over where they publish and even, in some cases, what they can say. But the irony is that many of the problems facing young researchers - and in particular the lack of support for highrisk research-appear to lie, not with external forces, but with forces that are under the control of the profession - namely the behaviour of senior IB scholars as journal editors, referees, publishers' advisors, line managers, and so on.

I have taken great pride in my role as a judge for the Buckley and Casson AIB Dissertation Award. The award rewards not only the winner, but all the finalists, who have a wonderful opportunity to showcase their work. It is disappointing for those who did not get short-listed, but they know that they have the confidence of the supervisors who nominated them and who will support them throughout their careers. But the Buckley and Casson Award, however admirable, is not, by itself, enough. In my view the IB community needs more follow-up initiatives to support the entrants and finalists in their early careers, and indeed to support early-career researchers in general too. Conference organizers already do a great job in encouraging young scholars through paper development workshops and networking events. But I see a certain irony in the fact that so many paper development workshops necessarily concentrate on the purely tactical aspects of publication rather than the intellectual challenge of high-risk research. Too much energy is dissipated in compensating for shortcomings elsewhere in the system. Organizational analysis suggests that the most effective approach to tackling a problem is to tackle it at its source. That problem, in my view, lies, at least in part, with IB journals and their aversion to high-risk research. 
Aversion to high-risk research is not unique to IB studies, of course, but I think it is worse in IB than in some other fields. Most of our finalists this year were working at the interface of IB studies with another field. This is probably no accident. Interacting with diverse literatures is intellectually stimulating, as it challenges the scholar to reconcile the different perspectives involved. It may be worthwhile for our finalists to publish in these other fields as well. Deans sometimes consider that faculty publishing outside their designated field are wasting their time, but this merely reflects the short-term instrumentalist perspective that I mentioned above. Young researchers need to recognize that their career may last for 40 years or more, and so they need to take a long-term view. Of course they need a short-term survival strategy, but this should not eclipse long-term ambition. Depending on their specific subject, high-risk IB scholars have an opportunity to publish in fields outside mainstream business and management studies. For example, some of this year's finalists could publish in business economics, business history, innovation studies, economic geography, international political economy, and development studies. Such publications might well have limited impact in passing probation and gaining tenure, but they can have a big impact later when applying for chairs. Chair committees often look for evidence of high-risk outputs in a variety of fields because they recognize this as a sign of leadership potential. There is a serious shortage of high-risk researchers at professorial level because so many academics become low-risk researchers in early career as part of their survival strategy. Once you become a low-risk researcher, it is almost impossible to reverse the process.

If our young high-risk researchers "keep the faith," and continue to broaden their intellectual horizons, then they may mature into senior academics with real leadership potential. They can take on the responsibilities of mentoring, editorship and faculty administration, and re-introduce a culture of high-risk research into IB. Who knows? One day they may become members of the Buckley and Casson AIB Dissertation Award judges panel themselves.

Mark Casson is Professor of Economics and Director of the Centre for Institutional Performance at the University of Reading. His recent publications include Markets and Market Institutions: Their Origins and Evolution (edited, 2011); The Entrepreneur in History (with Catherine Casson, 2013) and Large Databases in Economic History (edited with Nigar Hashimzade, 2013). He currently researches international business theory, the history of entrepreneurship, the impact of railroads on local population growth, and medieval property markets. 